\title{
Soluble Copolyimides Based on 2,3,5-Tricarboxycyclopentyl Acetic Dianhydride and Conventional Aromatic Tetracarboxylic Dianhydrides
}

\author{
Yusuke Tsuda, Kenichi Etou, Norihiko Hiyoshi, ${ }^{*}$ Michinori Nishikawa, ${ }^{* *}$ \\ Yasuo MATSUKI, ${ }^{* *}$ and Nobuo BeSSHO** \\ Department of Industrial Chemistry, Kurume National College of Technology, \\ 1232 Komorino-machi, Kurume, Fukuoka 830, Japan \\ * Advanced Engineering School, Kurume National College of Technology, \\ 1232 Komorino-machi, Kurume, Fukuoka 830, Japan \\ ** Yokkaichi Research Laboratories, Japan Synthetic Rubber Co., Ltd., \\ 100 Kawajiri-cho, Yokkaichi, Mie 510, Japan
}

(Received August 14, 1997)

\begin{abstract}
Soluble copolyimides based on 2,3,5-tricarboxycyclopentyl acetic dianhydride (TCA-AH)/aromatic tetracarboxilic dianhydrides/diamino diphenyl ether (DDE) were obtained. The maximum incorporation ratios of aromatic dianhydrides depend on flexibility of the dianhydrides. The ratios increase in the order of pyromellitic dianhydride (PMDA)

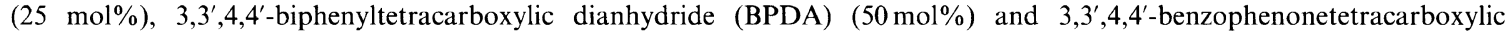
dianhydride (BTDA) $(65 \mathrm{~mol} \%)$. The incorporation of conventional aromatic tetracarboxilic dianhydrides results in improvement of the thermal stability of soluble polyimides based on TCA-AH by the increment of aromatic components in polymer backbone, and the reduction of amount of a special monomer, that is TCA-AH.

KEY WORDS Polyimide / Soluble Polyimide / Copolymerization / 2,3,5-Tricarboxycyclopentyl Acetic Dianhydride / Soluble Copolyimide / Thermal Stability /
\end{abstract}

Polyimides exhibit excellent thermal and mechanical properties, and have extensive engineering and microelectronics applications. ${ }^{1}$ Aromatic polyimides such as pyromellitic polyimides are prepared from aromatic diamines and aromatic tetracarboxylic dianhydrides via poly(amic acid)s. Since conventional aromatic polyimides are insoluble, these polymers are usually processed as the corresponding soluble poly(amic acid) precursors, and then either thermally or chemically imidized. However, there are some problems owing to the unstability of poly(amic acid)s and the liberation of water in imidization process. Therefore, solvent soluble polyimides processed without difficulty are desired. The solubility of the polyimides has been successfully improved by the incorporation of fluorine moieties ${ }^{2-6}$ or, chlorine moieties $^{7}$ or, bulky side groups ${ }^{8}$ or, pendant phenyl groups $^{9}$ or, polydimethylsiloxane segment, ${ }^{10}$ or polyalicyclic structures ${ }^{11-13}$ into the polymer backbone. Because these modifications are generally carried out using relatively expensive special monomers, soluble polyimide copolymers which consist of common aromatic dianhydrides and diamines have been also investigated. ${ }^{14}$

Recently the authors reported the synthesis and characterization of soluble polyimides prepared from an alicyclic tetracarboxylic dianhydride, 2,3,5-tricarboxycyclopentyl acetic dianhydride (TCA-AH), and aromatic diamines. ${ }^{15}$ TCA-AH polyimides exhibited good thermal stability and $10 \%$ weight loss temperatures were in the range of $422-470^{\circ} \mathrm{C}$ in air and $457-494^{\circ} \mathrm{C}$ in nitrogen. These temperatures are about $100^{\circ} \mathrm{C}$ lower than the values of aromatic soluble polyimides based on fluorin containing monomers such as 4,4'-hexafluoroisopropylidenedi(phthalic anhydride) (6FDA). This paper reports the synthesis and characterization of soluble copolyimides based on TCA-AH and conven- tional aromatic tetracarboxylic dianhydrides such as pyromellitic dianhydride (PMDA), 3,3',4,4'-biphenyltetracarboxylic dianhydride (BPDA), 3,3',4,4'-benzophenonetetracarboxylic dianhydride (BTDA). The object of this study is to reduce the amounts of TCA-AH in soluble polyimides and enhance thermal stability by increment of aromatic components in the polymer backborns. The above conventional aromatic dianhydrides are commercially available and relatively inexpensive, while TCA$\mathrm{AH}$ belongs to special monomers. Therefore, reduction of the amount of TCA-AH may be more economical. Soluble copolyimides based on 6FDA, known to give soluble polyimides by the effect of two trifluoro methyl groups, with conventional aromatic dianhydrides were used for reference. The authors chose 4,4'diaminodiphenylether (DDE) as an aromatic diamine for these copolyimides because it is one of the most representative diamine monomers for aromatic polyimide syntheses.

\section{EXPERIMENTAL}

\section{Materials}

TCA-AH (mp $194-195^{\circ} \mathrm{C}$ from acetic anhydride) was kindly supplied by Japan Synthetic Rubber Co., Ltd. PMDA (Mitsubishi Gas Chemical), BTDA (Mitsui Toatsu Chemicals Inc.), BPDA (Ube Industries, Ltd.), 6FDA (Central Glass Co., Ltd.), and DDE (Wakayama Seika Kogyo Co., Ltd.) were used as received. $N$-Methyl2-pyrrolidone (NMP) (Mitsubishi Kasei) were distilled under reduced pressure. Reagent grade acetic anhydride and pyridine were purchased from Katayama Chemical Industries Co., Ltd. and used as received. Dimethyl sulfoxide- $d_{6}$ (Aldrich Chem. Co.) was used as received.

\section{Measurement}

The inherent viscosities of all polymers were measured 
using Cannon Fenske viscometers at a concentration of $0.5 \mathrm{~g} \mathrm{dL}^{-1}$ in NMP at $30^{\circ} \mathrm{C}$. Thermogravimetric analysis (TGA) was performed on a Shimadzu thermogravimetric analyzer Model TGA-50 in air or nitrogen at a heating rate of $10^{\circ} \mathrm{Cmin}^{-1} \cdot{ }^{1} \mathrm{H}$ NMR spectra were measured on a JEOL JNM-EX270 FT NMR in dimethyl sulfoxide- $d_{6}$ with tetramethylsilane (TMS) as the internal reference. IR spectra were measured on a JASCO IR Report-100 spectrophotometer.

\section{Poly(amic acid) Preparations}

As a typical example, to a $30-\mathrm{mL}$ flask were added $0.596 \mathrm{~g}(2.66 \mathrm{mmol}, 75 \mathrm{~mol} \%$ of the amount of tetracarboxilic dianhydrides) of TCA-AH, $0.193 \mathrm{~g}$ (0.89 mmol, $25 \mathrm{~mol} \%$ of the amount of tetracarboxilic dianhydrides) of PMDA and $0.710 \mathrm{~g}(3.55 \mathrm{mmol})$ of DDE. The system was purged by nitrogen and NMP was added. Monomer concentration was kept at $10 \mathrm{wt} \%$. The mixture was stirred at $60^{\circ} \mathrm{C}$ under nitrogen for $12 \mathrm{~h}$ to allow viscosity to increase. About one-third of the reaction mixture was poured into a large amount of water or methanol. Precipitated poly(amic acid) was filtered, washed with methanol and dried at room temperature for 2 days. The residual two-thirds of the poly(amic acid) solution was used for the following polyimide preparation. The IR spectrum $(\mathrm{KBr})$ exhibited absorptions at $3300 \mathrm{~cm}^{-1}(\mathrm{O}-\mathrm{H}$ and $\mathrm{N}-\mathrm{H}), 1725$ and $1680 \mathrm{~cm}^{-1}$ $(\mathrm{C}=\mathrm{O})$. Chemical shifts of the characteristic absorption peaks of ${ }^{1} \mathrm{H}$ NMR spectra and results of elemental analysis are as follows. ${ }^{1} \mathrm{H}$ NMR (DMSO): $\delta(\mathrm{ppm})=c a$. $1.8-4.0$ (m, aliph.), $6.8-7.2(\mathrm{~m}$, arom.), 7.4-7.8 (m, arom.), 7.95 (s, arom.), 9.96-10.06 (m, -NH-). Anal. Calcd for $\left[0.75 \times\left(\mathrm{C}_{22} \mathrm{H}_{20} \mathrm{~N}_{2} \mathrm{O}_{7}\right)_{n}+0.25 \times\left(\mathrm{C}_{22} \mathrm{H}_{14} \mathrm{~N}_{2}\right.\right.$ $\left.\left.\mathrm{O}_{7}\right)_{n}\right]$ : C, 62.49\%; H, 4.41\%; N, 6.63\%. Found: C, $60.55 \% ; \mathrm{H}, 5.35 \% ; \mathrm{N}, 7.83 \%$. The carbon analysis value was found lower than the calculated value and a trace amount of residue was observed after elemental analysis, probably due to the formation of char characteristic of heat resistant polymers. ${ }^{16}$

\section{Polyimide Preparations}

As a typical example, to $10 \mathrm{~g}$ of $10 \mathrm{wt} \% \mathrm{TCA}-\mathrm{AH} /$ PMDA/DDE poly(amic acid) solution were added $1 \mathrm{~g}$ of pyridine and $1 \mathrm{~g}$ of acetic anhydride. The system was purged by nitrogen and stirred at $110-120^{\circ} \mathrm{C}$ under nitrogen for $5 \mathrm{~h}$. Powdered polyimides were obtained by precipitation in a large amount of methanol, filtered, and washed with a large amount of methanol, and dried at $100^{\circ} \mathrm{C}$ for 1 day. The IR spectrum $(\mathrm{KBr})$ exhibited absorptions at 1730 and $1685 \mathrm{~cm}^{-1}(\mathrm{C}=\mathrm{O}), 1375 \mathrm{~cm}^{-1}$ $(\mathrm{C}-\mathrm{N})$. Chemical shifts of the characteristic absorption peaks of ${ }^{1} \mathrm{H}$ NMR spectra and results of elemental analysis are as follows. ${ }^{1} \mathrm{H}$ NMR (DMSO): $\delta(\mathrm{ppm})=c a$. $1.8-3.9$ (m, aliph), 6.85-7.75 (m, arom), 8.39 (s, arom.), 9.91-10.24 (m, unreacted - NH-). Detailed descriptions of ${ }^{1} \mathrm{H}$ NMR spectra will be given in the next section. Anal. Calcd for $\left[0.75 \times\left(\mathrm{C}_{22} \mathrm{H}_{16} \mathrm{~N}_{2} \mathrm{O}_{5}\right)_{n}+0.25 \times\left(\mathrm{C}_{22}-\right.\right.$ $\left.\mathrm{H}_{10} \mathrm{~N}_{2} \mathrm{O}_{5}\right)_{n}$ ]: C, 68.31\%; H, 3.77\%; N, 7.24\%. Found: C, $64.97 \% ; \mathrm{H}, 4.91 \%$; N, 8.15\%. The carbon analysis value was found lower than the calculated value and a trace amount of residue was observed after the elemental analysis as mentioned previously.
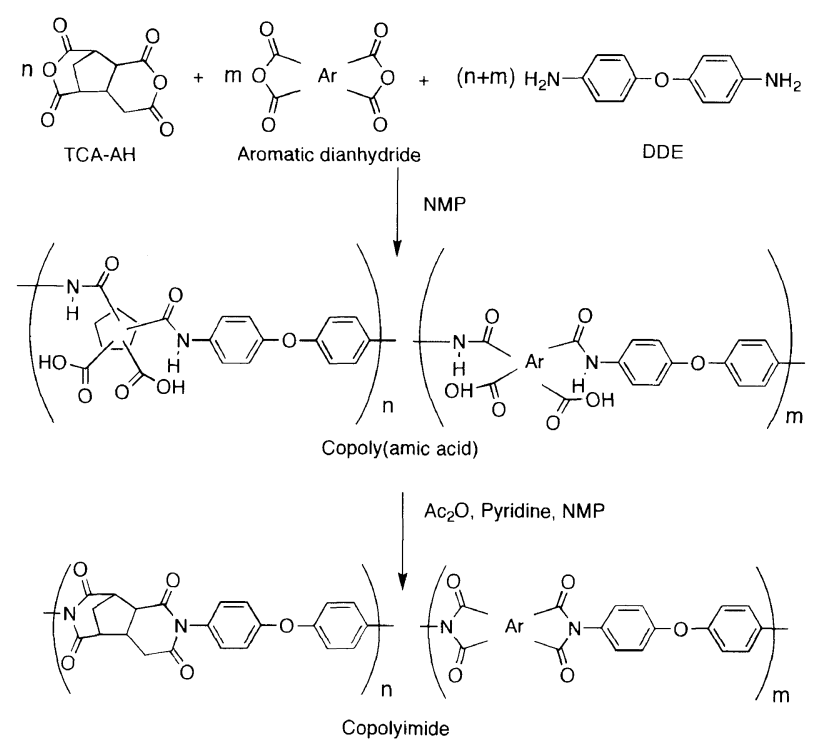

Aromatic dianhydride;
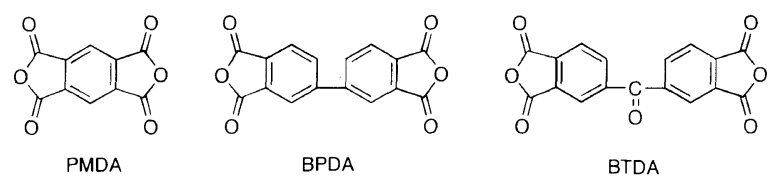

Scheme 1. Synthesis of copolyimides based on 2,3,5-tricarboxycyclopentylacetic dianhydride (TCA-AH), aromatic dianhydride and diamino diphenyl ether (DDE).

\section{RESULTS AND DISCUSSION}

The synthetic route of the copolyimides from TCA$\mathrm{AH}$, conventional tetracarboxilic dianhydrides and DDE is illustrated in Scheme 1. Two-step polymerization system including poly(amic acids) synthesis and solution imidization process was performed. The poly(amic acids) unit based on TCA-AH theoretically contains four isomers due to unsymmetrical structure of TCA-AH, while poly(amic acids) unit based on PMDA, BPDA or BTDA theoretically contains two or three isomers respectively. ${ }^{17}$ The copoly(amic acids) were obtained by reacting a mixture of $\mathrm{TCA}-\mathrm{AH}$ and aromatic dianhydride with an equimolar amount of DDE at $60^{\circ} \mathrm{C}$ for $12 \mathrm{~h}$ under a nitrogen atmosphere. Total moles of tetracarboxylic dianhydrides were adjusted accurately with the moles of DDE. The copolyimides were obtained by solution imidization at $110-120^{\circ} \mathrm{C}$ in the presence of pyridine as a base catalyst and acetic anhydride as a dehydrating agent. Aromatic copolyimides based on 6FDA and conventional tetracarboxilic dianhydrides with DDE were examined in the same manner as TCA-AH.

The experimental results of copolymerization based on TCA-AH/PMDA/DDE and 6FDA/PMDA/DDE are summarized in Table I. TCA-AH/DDE homopolyimide and TCA-AH/PMDA/DDE copolyimides containing $25 \mathrm{~mol} \%$ of PMDA or less were soluble in NMP, while the copolyimides containing $30 \mathrm{~mol} \%$ PMDA or more were insoluble in NMP because of the increment of aromatic components in the polymer backbone. In the case of soluble polyimides, clear polyimide solutions were eventually obtained. In other cases, clear poly(amic acid) 
Table 1. Copoly(amic acids) and corresponding copolyimides based on TCA-AH/PMDA/DDE and 6FDA/PMDA/DDE

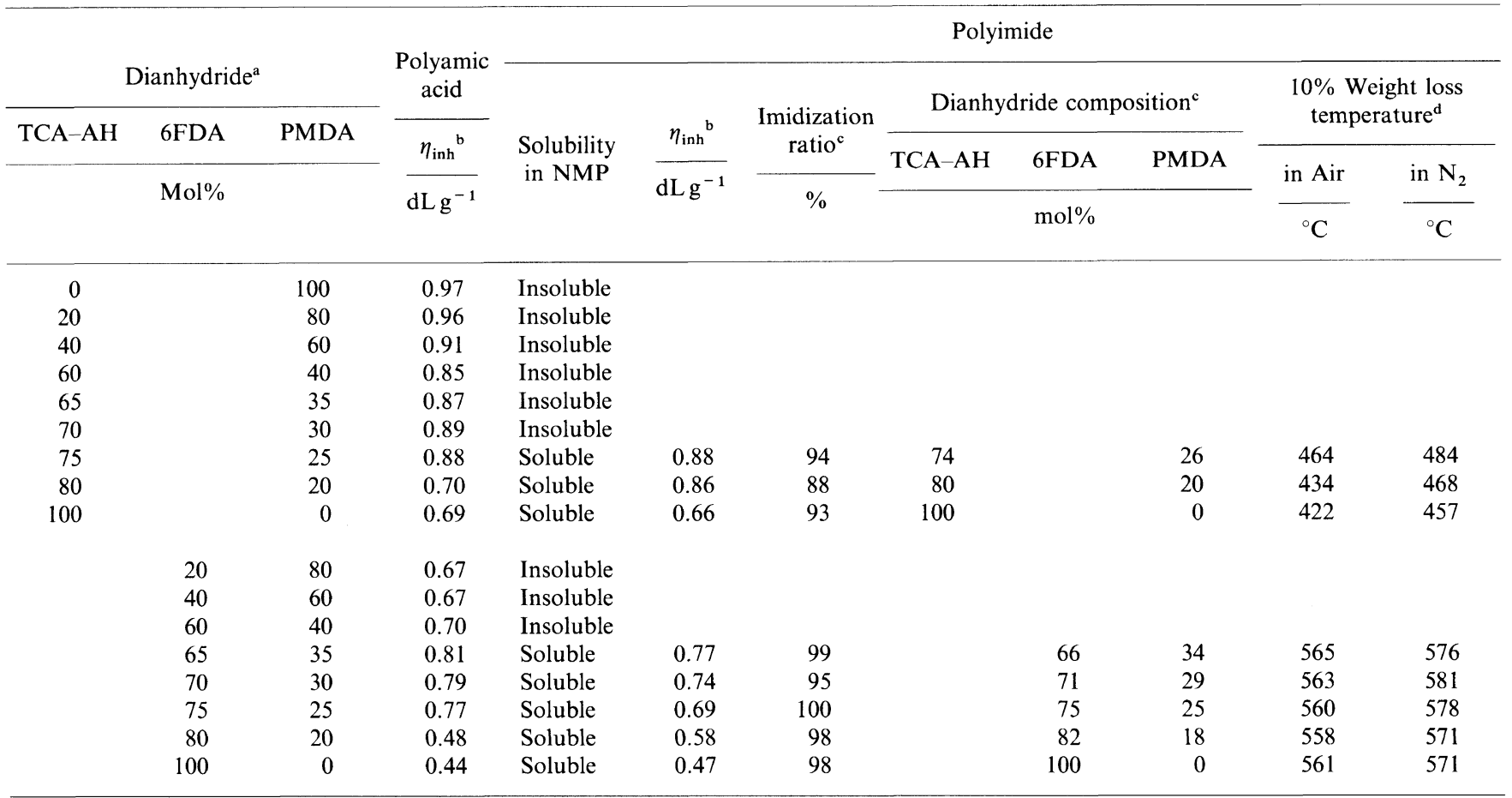

${ }^{a}$ Equimolar amount of DDE was used to the total amount of dianhydride. ${ }^{\mathrm{b}}$ Measured at $0.5 \mathrm{gdL}-1$ in $\mathrm{NMP}$ at $30^{\circ} \mathrm{C}$. ${ }^{\mathrm{c}} \mathrm{Calculated}$ from ${ }^{1} \mathrm{H}$ NMR measurement. ${ }^{d}$ Measured at a heating rate of $10^{\circ} \mathrm{C} \mathrm{min}^{-1}$.

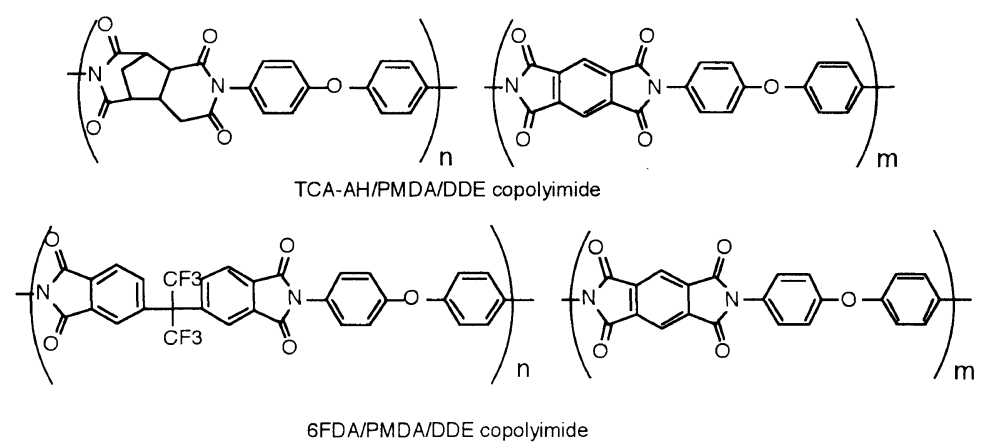

solutions were obtained as well. However, gelation or precipitation happened in the course of imidization. The inherent viscosities of above polyimides were high in the range of $0.66-0.88 \mathrm{dL} \mathrm{g}^{-1}$, suggesting that these soluble polyimides have high enough molecular weights.

Figure 1 shows a representative ${ }^{1} \mathrm{H}$ NMR spectrum of TCA-AH/PMDA/DDE copolyimides. Broad signals of aliphatic protons based on TCA-AH appear in the magnetic field of 1.8 to $3.9 \mathrm{ppm}$, while complicated aromatic proton signals based on DDE appear in the rang of 6.85 to $7.75 \mathrm{ppm}$ and a singlet aromatic signal based on PMDA appears at $8.39 \mathrm{ppm}$. Thus, dianhydride composition of TCA-AH/PMDA/DDE copolyimide is directly measured from the intensity ratio of PMDA aromatic protons and DDE aromatic protons. The dianhydride compositions in the final polymers calculated from ${ }^{1} \mathrm{H}$ NMR are in a fair agreement with the initial monomer compositions. The dianhydride compositions of TCA-AH/BPDA/DDE copolyimides, 6FDA/ BPDA/DDE copolyimides, TCA-AH/BTDA/DDE copolyimides, and 6FDA/BTDA/DDE copolyimides could not be calculated from the ${ }^{1} \mathrm{H}$ NMR spectra because of overlapping of the aromatic proton signals of BPDA or BTDA, and DDE. However, the dianhydride compositions of these copolyimides may be the same as the initial monomer compositions by the results of similar copolymer systems, TCA-AH/PMDA and 6FDA/PMDA/ DDE copolyimides. The imidization ratio was calculated from the intensity ratio of $\mathrm{NH}$ protons to all aromatic protons by the method previously reported. ${ }^{15}$ Imidization ratios of $\mathrm{TCA}-\mathrm{AH} / \mathrm{DDE}$ homopolyimide and TCA-AH/PMDA/DDE copolyimides were high in the range of $88-94 \%$. These results suggest that the solution imidization reaction proceeds almost quantitatively.

6FDA/PMDA/DDE copolyimides containing 35 $\mathrm{mol} \%$ of PMDA or less were soluble in NMP, while the copolyimides containing $40 \mathrm{~mol} \%$ of PMDA or more were insoluble in NMP. These soluble copolyimides have high enough inherent viscosities and imidization ratios. The dianhydride compositions of 6FDA/PMDA/DDE copolyimides were measured from ${ }^{1} \mathrm{H}$ NMR measurement and well agreed with the initial monomer compositions.

The thermal stability of these soluble copolyimides 

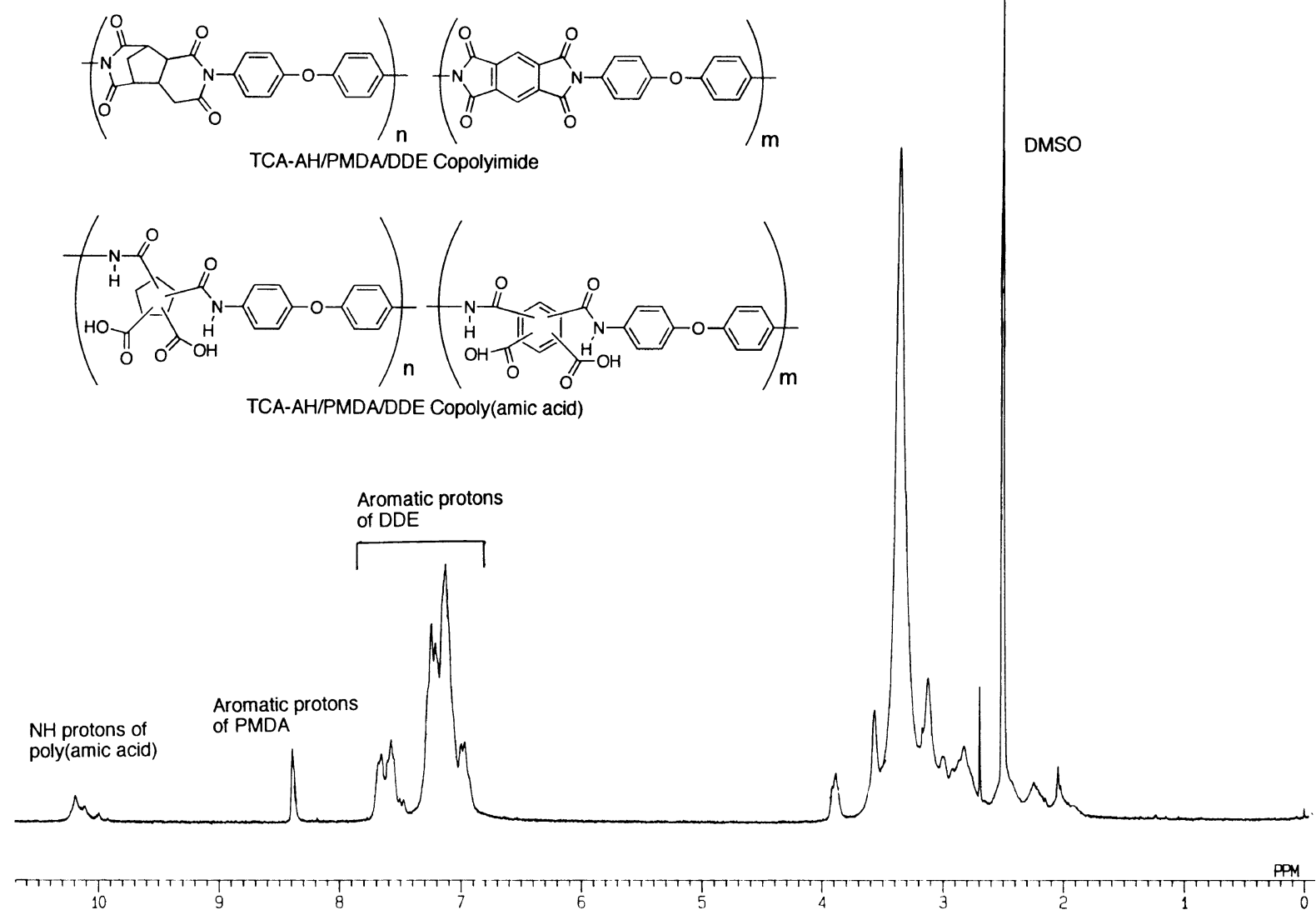

Figure 1. ${ }^{1} \mathrm{H}$ NMR spectrum of a representative TCA-AH copolyimide (TCA-AH/PMDA/DDE).

were evaluated by $10 \%$ weight loss temperatures in TGA. measurements. Ten percent weight loss temperatures of TCA-AH/DDE homopolyimide and TCA-AH/PMDA/ DDE copolyimides were in the range of $422-464^{\circ} \mathrm{C}$ in air and $457-484^{\circ} \mathrm{C}$ in nitrogen and these temperatures rose with PMDA segment. 6FDA/DDE homopolyimide and $6 \mathrm{FDA} / \mathrm{PMDA} / \mathrm{DDE}$ copolyimides were in the range of $561-565^{\circ} \mathrm{C}$ in air and $571-576^{\circ} \mathrm{C}$ in nitrogen. Two tetracarboxylic dianhydrides in above 6FDA-based soluble copolyimides are both aromatic monomers, and thus $10 \%$ weight loss temperatures are almost constant independent of dianhydride compositions.

The experimental results of copolymerization based on TCA-AH/BPDA/DDE and 6FDA/BPDA/DDE, TCAAH/BTDA/DDE and 6FDA/BTDA /DDE are summarized in Tables II and III respectively. TCA-AH/BPDA/ DDE copolyimides and 6FDA/BPDA/DDE copolyimides containing less or equal to $50 \mathrm{~mol} \%$ of BPDA or less were soluble in NMP, while both TCA-AH/ BTDA/DDE copolyimides and 6FDA/BTDA/DDE copolyimides containing $65 \mathrm{~mol} \%$ of BTDA or less were soluble in NMP. Figure 2 summarizes the results of the incorporation of aromatic tetracarboxilic dianhydrides into the TCA-AH/DDE and 6FDA/DDE soluble polyimides. The maximum incorporation ratios of conventional aromatic tetracarboxilic dianhydrides depend on the flexibility of these dianhydrides, which affects the solubility of the resulting polymers. BPDA and BTDA have rotative $s p^{2} \mathrm{C}-\mathrm{C}$ bonds between two benzene rings. A comparison of TCA-AH-based soluble polyimides with 6FDA-based soluble polyimides shows the maxi- mum incorporation ratios by mole are equal or higher in 6FDA-based soluble polyimides than in TCA-AHbased soluble polyimides. These ratios by weight are higher in TCA-AH-based soluble polyimides than in 6FDA-based ones. This difference is probably based on the fact that the effect on solubility per weight unit is higher in TCA-AH than in 6FDA. One purpose of copolymerization of conventional aromatic tetracarboxilic dianhydrides is to reduce the amounts of special monomers. In industry, the ingredients of polymers are charged by weight. Therefore, it can be assumed that the reduction of special monomers is achieved advantageously in TCA-AH-based soluble copolyimides than in 6FDA-based soluble copolyimides.

Inherent viscosities, an index of molecular weights of these copolyimides, tend to increase in the order of BPDA-based copolyimides (Table II), BTDA-based copolyimides (Table III), and PMDA based copolyimides (Table I). This is probably due to the deference of reactivity of aromatic tetracarboxilic dianhydrides and follows the value of electron affinity previously reported; BPDA $\left(E_{\mathrm{a}}=1.38 \mathrm{eV}\right)$, BTDA $\left(E_{\mathrm{a}}=1.55 \mathrm{eV}\right)$, and PMDA $\left(E_{\mathrm{a}}=1.90 \mathrm{eV}\right) .{ }^{18}$ Ten percent weight loss temperatures of TCA-AH/BPDA/DDE copolyimides increased by increment of BPDA component and the maximum temperature reached $451{ }^{\circ} \mathrm{C}$ in air and $473{ }^{\circ} \mathrm{C}$ in nitrogen, respectively (Table II). These temperatures of TCA-AH/ BTDA/DDE copolyimides increased by the increment of BPDA component and the highest temperature reached $482^{\circ} \mathrm{C}$ in air and $519^{\circ} \mathrm{C}$ in nitrogen respectively (Table III, Figure 3). It was confirmed that the thermal stability 
Table II. Copoly(amic acids) and the corresponding copolyimides based on TCA-AH/BPDA/DDE and 6FDA/BPDA/DDE

\begin{tabular}{|c|c|c|c|c|c|c|c|c|}
\hline \multirow{2}{*}{\multicolumn{3}{|c|}{ Dianhydride $^{a}$}} & \multirow{5}{*}{$\frac{\begin{array}{c}\text { Polyamic } \\
\text { acid }\end{array}}{\frac{\eta_{\mathrm{inh}}^{\mathrm{b}}}{\mathrm{dL} \mathrm{g}^{-1}}}$} & \multicolumn{5}{|c|}{ Polyimide } \\
\hline & & & & \multirow{4}{*}{$\begin{array}{l}\text { Solubility } \\
\text { in NMP }\end{array}$} & \multirow{4}{*}{$\frac{\eta_{\mathrm{inh}}^{\mathrm{b}}}{\mathrm{dLg}^{-1}}$} & \multirow{4}{*}{$\frac{\begin{array}{c}\text { Imidization } \\
\text { ratio }^{c}\end{array}}{\%}$} & \multirow{2}{*}{\multicolumn{2}{|c|}{$\begin{array}{l}10 \% \text { Weight loss } \\
\text { temperature }^{\mathrm{d}}\end{array}$}} \\
\hline \multirow{3}{*}{ TCA-AH } & \multirow{3}{*}{$\begin{array}{l}6 \mathrm{FDA} \\
\mathrm{mol} \%\end{array}$} & \multirow{3}{*}{ BPDA } & & & & & & \\
\hline & & & & & & & in Air & in $\mathrm{N}_{2}$ \\
\hline & & & & & & & ${ }^{\circ} \mathrm{C}$ & ${ }^{\circ} \mathrm{C}$ \\
\hline 0 & & 100 & 0.34 & Insoluble & & & & \\
\hline 40 & & 60 & 0.35 & Insoluble & & & & \\
\hline 50 & & 50 & 0.39 & Soluble & 0.43 & 92 & 451 & 473 \\
\hline 60 & & 40 & 0.42 & Soluble & 0.36 & 96 & 449 & 472 \\
\hline 80 & & 20 & 0.50 & Soluble & 0.39 & 90 & 434 & 464 \\
\hline 100 & & 0 & 0.69 & Soluble & 0.66 & 93 & 422 & 457 \\
\hline & 40 & 60 & 0.34 & Insoluble & & & & \\
\hline & 50 & 50 & 0.34 & Soluble & 0.36 & 95 & 574 & 595 \\
\hline & 60 & 40 & 0.38 & Soluble & 0.35 & 93 & 574 & 581 \\
\hline & 80 & 20 & 0.48 & Soluble & 0.43 & 97 & 564 & 580 \\
\hline & 100 & 0 & 0.44 & Soluble & 0.47 & 98 & 561 & 571 \\
\hline
\end{tabular}

${ }^{a}$ Equimolar amount of DDE was used to the amount of dianhydrides. ${ }^{b}$ Measured at $0.5 \mathrm{gdL}^{-1}$ in NMP at $30^{\circ} \mathrm{C}$. ${ }^{\mathrm{c}}$ Calculated from ${ }^{1} \mathrm{H}$ NMR measurement. ${ }^{\mathrm{d}}$ Measured at a heating rate of $10^{\circ} \mathrm{C} \mathrm{min}^{-1}$.

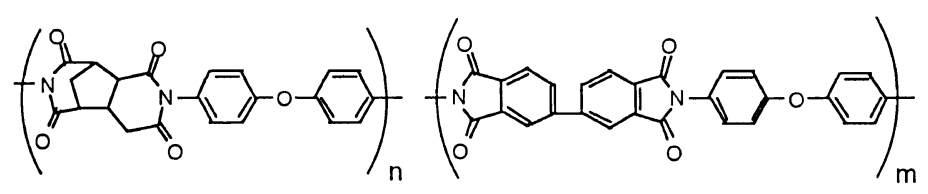

TCA-AH/BPDA/DDE copolyimide

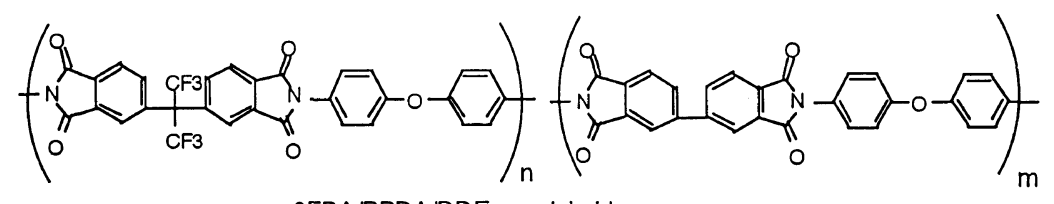

6FDA/BPDA/DDE copolyimide

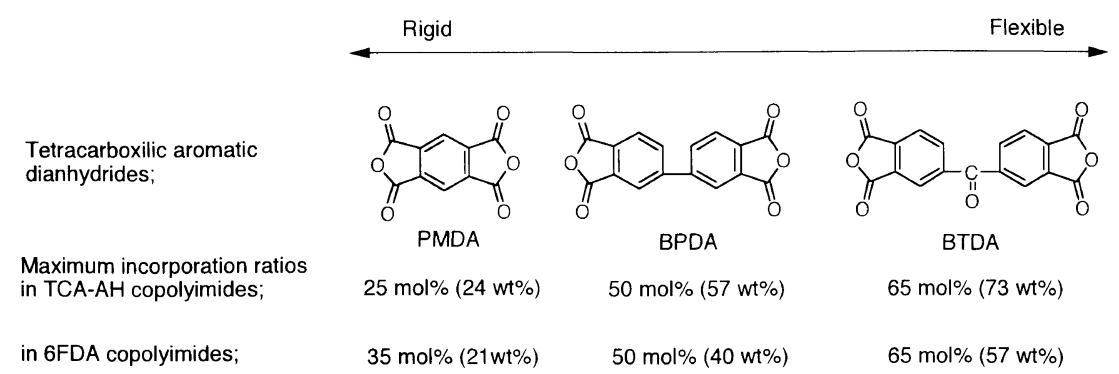

Figure 2. Results of incorporation of aromatic tetracarboxilic dianhydrides into the TCA-AH/DDE and 6FDA/DDE soluble polyimides.

of the soluble polyimide based on TCA-AH was improved by the incorporation of aromatic tetracarboxilic dianhydrides up to approximately $500^{\circ} \mathrm{C}$, which was the value near those of wholly aromatic polyimides.

\section{CONCLUSIONS}

Soluble copolyimides based on TCA-AH/aromatic tetracarboxilic dianhydrides/DDE were obtained. The maximum incorporation ratios of aromatic tetracarboxilic dianhydrides depended on the flexibility of these dianhydrides. These ratios increased in the order of PMDA $(25 \mathrm{~mol} \%)$, BPDA $(50 \mathrm{~mol} \%)$ and BTDA $(65 \mathrm{~mol} \%)$. In soluble polyimides based on 6FDA, incorporation was similarly possible. However, more weight percent of conventional aromatic tetracarboxilic dianhydrides could be incorporated in soluble polyimides based on TCA-AH. The incorporation of aromatic tetracarboxilic dianhydrides resulted in the improvement of the thermal stability of soluble polyimides based on TCA-AH. In TCA-AH/BTDA/DDE soluble copolyimides, $10 \%$ weight loss temperature of $482^{\circ} \mathrm{C}$ in air and $519^{\circ} \mathrm{C}$ in nitrogen reached the values near those of aromatic polyimides. The authors are convinced that these examples of copolymerization using special monomers and conventional monomers could be applied in a variety of soluble polyimide systems. 
Table III. Copoly(amic acids) and the corresponding copolyimides based on TCA-AH/BTDA/DDE and 6FDA/BTDA/DDE

\begin{tabular}{|c|c|c|c|c|c|c|c|c|}
\hline \multirow{2}{*}{\multicolumn{3}{|c|}{ Dianhydride $^{\mathrm{a}}$}} & \multirow{5}{*}{$\frac{\begin{array}{c}\text { Polyamic } \\
\text { acid }\end{array}}{\frac{\eta_{\text {inh }}{ }^{\mathrm{b}}}{\mathrm{dL} \mathrm{g}^{-1}}}$} & \multicolumn{5}{|c|}{ Polyimide } \\
\hline & & & & \multirow{4}{*}{$\begin{array}{l}\text { Solubility } \\
\text { in NMP }\end{array}$} & \multirow{4}{*}{$\frac{\eta_{\mathrm{inh}}{ }^{\mathrm{b}}}{\mathrm{d} \mathrm{Lg}^{-1}}$} & \multirow{4}{*}{$\frac{\begin{array}{c}\text { Imidization } \\
\text { ratio }^{c}\end{array}}{\%}$} & \multirow{2}{*}{\multicolumn{2}{|c|}{$\begin{array}{l}10 \% \text { Weight loss } \\
\text { temperature }^{\mathrm{d}}\end{array}$}} \\
\hline \multirow[t]{3}{*}{ TCA-AH } & \multirow{3}{*}{$\frac{6 \mathrm{FDA}}{\mathrm{mol} \%}$} & \multirow[t]{3}{*}{ BTDA } & & & & & & \\
\hline & & & & & & & \multirow{2}{*}{$\frac{\text { in } \mathrm{Air}}{{ }^{\circ} \mathrm{C}}$} & \multirow{2}{*}{$\frac{\text { in } \mathrm{N}_{2}}{{ }^{\circ} \mathrm{C}}$} \\
\hline & & & & & & & & \\
\hline 0 & & 100 & 0.73 & Insoluble & & & & \\
\hline 20 & & 80 & 0.75 & Insoluble & & & & \\
\hline 30 & & 70 & 0.77 & Insoluble & & & & \\
\hline 35 & & 65 & 0.75 & Soluble & 0.69 & 100 & 482 & 519 \\
\hline 40 & & 60 & 0.70 & Soluble & 0.70 & 98 & 477 & 511 \\
\hline 60 & & 40 & 0.72 & Soluble & 0.66 & 93 & 479 & 490 \\
\hline 80 & & 20 & 0.73 & Soluble & 0.70 & 91 & 444 & 480 \\
\hline \multirow[t]{8}{*}{100} & & 0 & 0.69 & Soluble & 0.66 & 03 & 422 & 457 \\
\hline & 20 & 80 & 0.71 & Insoluble & & & & \\
\hline & 30 & 70 & 0.64 & Insoluble & & & & \\
\hline & 35 & 65 & 0.66 & Soluble & 0.56 & 100 & 565 & 595 \\
\hline & 40 & 60 & 0.58 & Soluble & 0.65 & 96 & 566 & 590 \\
\hline & 60 & 40 & 0.57 & Soluble & 0.60 & 100 & 562 & 589 \\
\hline & 80 & 20 & 0.56 & Soluble & 0.59 & 100 & 556 & 578 \\
\hline & 100 & 0 & 0.44 & Soluble & 0.47 & 98 & 561 & 571 \\
\hline
\end{tabular}

${ }^{\text {a }}$ Equimolar amount of DDE was used to the amount of dianhydrides. ${ }^{b}$ Measured at $0.5 \mathrm{~g} \mathrm{dL}^{-1}$ in NMP at $30^{\circ} \mathrm{C}$. ${ }^{\mathrm{c}}$ Calculated from ${ }^{1} \mathrm{H}$ NMR measurement. ${ }^{\mathrm{d}}$ Measured at a heating rate of $10^{\circ} \mathrm{C} \mathrm{min}^{-1}$.

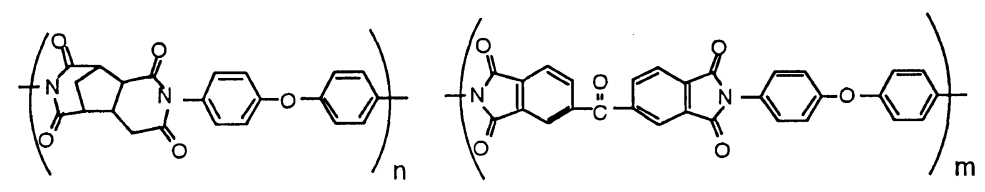

TCA-AH/BTDA/DDE copolyimide

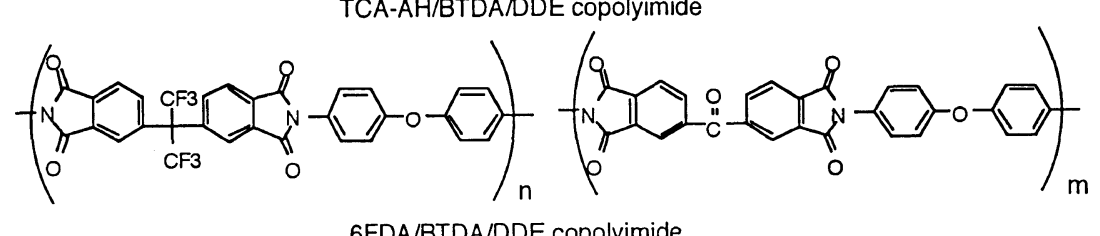

6FDA/BTDA/DDE copolyimide

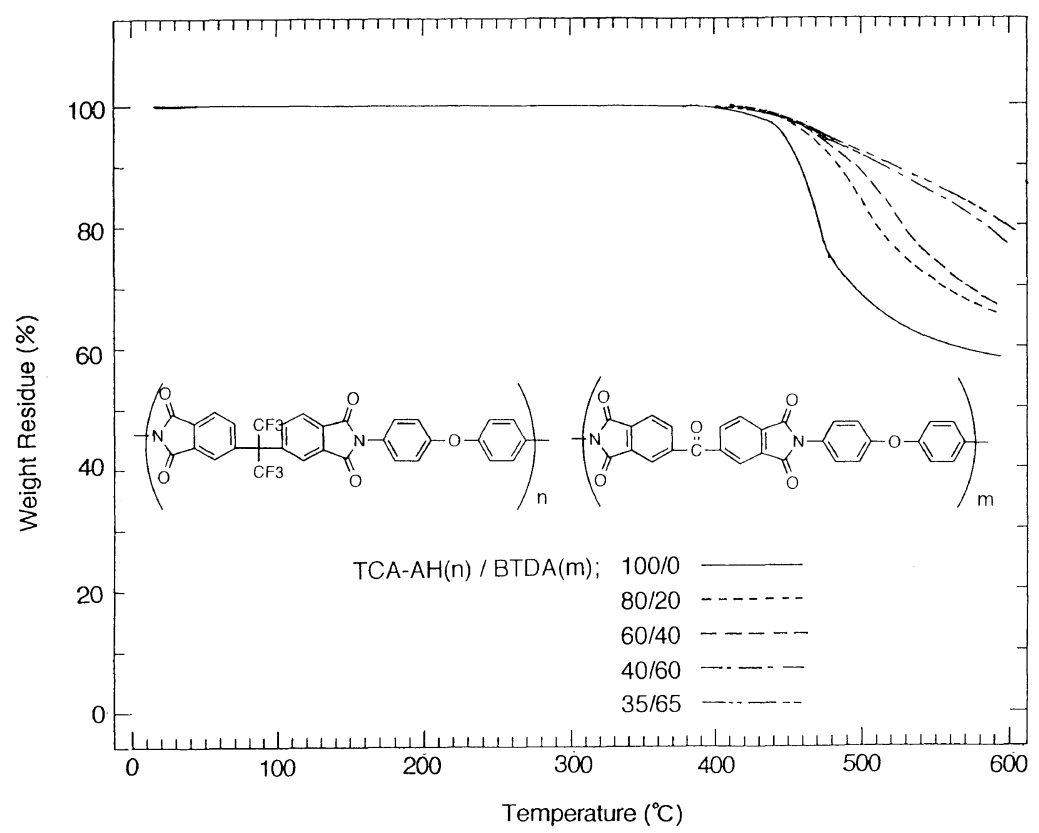

Figure 3. TGA curves of a representative TCA-AH copolyimides (TCA-AH/BTDA/DDE). 
Acknowledgments. The authors thank Dr. Yoshiyuki Oishi of Iwate University, Drs. Shuntaro Mataka and Atsushi Takahara of Kyushu University, and Dr. Virgil Percec of Case Western Reserve University for valuable advises. Thanks are due to Ms. Junko Akiyoshi, Advanced Engineering School, Kurume National College of Technology, for assistance with thermogravimetric analysis. Financial support from Technopolis Foundation of Kurume-Tosu is gratefully acknowledged.

\section{REFERENCES}

1. K. L. Mittal, "Polyimides," Plenum Press, New York, N.Y., 1984.

2. J. E. McGrath, M. E. Rogers, C. A. Arnold, Y. J. Kim, and J. C. Hedrick, Macromol. Chem., Macromol. Symp., 51, 103 (1991).

3. S. Z. D. Cheng, F. E. Arnold, Jr., A. Zhang, S. L.-C. Hsu, and F. W. Harris, Macromolecules, 24, 5856 (1991).

4. F. E. Arnold, Jr., S. Z. D. Cheng, S. L.-C. Hsu, C. J. Lee, F. W. Harris, and S.-F. Lau, Polymer, 33, 5179 (1992).

5. M. E. Rogers, M. H. Brink, J. E. McGrath, and A. Brennan, Polymer, 34, 849 (1993).

6. J. W. Park, M. Lee, M.-H. Lee, J. W. Liu, S. D. Kim, J. Y.
Chang, and S. B. Rhee, Macromolecules, 27, 3459 (1994).

7. P. A. Falcigno, S. Jasne, and M. King, J. Polym. Sci., Polym. Chem. Ed., 30, 1433 (1992).

8. C.-P. Yang and J.-H. Lin, J. Polym. Sci., Polym. Chem. Ed., 32, 423 (1994).

9. Y. Oishi, M. Ishida, M. Kakimoto, Y. Imai, and T. Kurosaki, J. Polym. Sci., Polym. Chem. Ed., 30, 1027 (1992).

10. C. A. Arnold, J. D. Summers, Y. P. Chen, R. H. Bott, D. Chen, and J. E. McGrath, Polymer, 30, 986 (1989).

11. S. Itamura, M. Yamada, S. Tamura, T. Matsumoto, and T. Kurosaki, Macromolecules, 26, 3940 (1993).

12. M. Yamada, M. Kusama, T. Matsumoto, and T. Kurosaki, Macromolecules, 26, 4961 (1993).

13. M. Kusama, T. Matsumoto, and T. Kurosaki, Macromolecules, 27, 1117 (1994).

14. R. G. Bryant, ACS Polymer Preprints, 35, 517 (1994).

15. Y. Tsuda, Y. Tanaka, K. Kamata, N. Hiyoshi, S. Mataka, Y. Matsuki, M. Nishikawa, S. Kawamura, and N. Bessho, Polym. J., 29, 574 (1997).

16. Y. Oishi, M. Ishida, H. Takado, M. Yoneyama, M. Kakimoto, and Y. Imai, J. Polym. Sci., Polym. Chem. Ed., 28, 1763 (1990)

17. V. M. Denisov, V. M. Svetlichnyi, A. Gindin, V. A. Zubkov, A. I. Kol'tsov, M. M. Koton, and V. V. Kudryavtsev, Polym. Sci. USSR, A21, 1644 (1979).

18. T. Takekoshi, in "Polyimides," M. K. Ghosh, and K. L. Mittal, Ed., Marcel Dekker, New York, N.Y., 1996, p 10. 